\title{
PAPERS
}

\section{Rapid diagnosis of acute meningococcal infections by needle aspiration or biopsy of skin lesions}

\author{
Marcel van Deuren, Beatrix J van Dijke, Roland J J Koopman, Alfons M Horrevorts, \\ Jacques F G M Meis, Frederik W Santman, Jos W M van der Meer
}

\begin{abstract}
Objectives-To evaluate the usefulness of Gram staining and culture of skin lesions in patients with acute meningococcal infections.

Design-Retrospective study.

Setting-Community hospital and intensive care unit of a teaching hospital.

Subjects-51 patients admitted from 1989 to 1993 with proved meningococcal infections and microbiological examination of specimens from skin lesions.
\end{abstract}

Interventions-Needle aspiration of a skin lesion before start of antibiotic treatment in 26 patients in the community hospital; punch biopsy of skin lesion after start of antibiotic treatment in 25 patients in the teaching hospital.

Main outcome measures-Detection of meningococci by Gram staining of specimens from skin lesions according to category of infection (meningococcaemia, meningitis, meningitis with shock, or septic shock without meningitis).

Results-Bacteria were detected in the specimen from haemorrhagic skin lesions by culture or Gram staining, or both in $32(63 \%)$ patients. The sensitivity of the Gram stain was $51 \%$ and did not differ significantly from its sensitivity in detecting bacteria in cerebrospinal fluid. In meningococcal sepsis, however, a Gram stained skin lesion was significantly more sensitive $(72 \%)$ than Gram stained cerebrospinal fluid $(22 \%)$. In patients with meningitis skin lesions gave positive results on staining more often if shock was present. The results for punch biopsy specimens were not affected by antibiotics as Gram staining gave positive results up to 45 hours after the start of treatment and culture gave positive results up to 13 hours.

Conclusion-Microbiological examination of skin lesions is informative, especially in patients with sepsis and inconclusive results from cerebrospinal fluid, and may provide a diagnosis in such patients within 45 minutes. It differentiates well between meningitis with and without haemodynamic complications, and the result is not affected by previous antibiotic treatment.

\section{Introduction}

Acute infections with Neisseria meningitidis are life threatening, with an overall mortality of about $10 \%$. The clinical manifestations range from meningococcaemia without circulatory impairment to meningitis and sepsis. ${ }^{1}$ The mortality from meningococcaemia without shock is negligible, from meningitis is $1-5 \%$, and from sepsis is $30-70 \% .^{2-6}$ Roughly two thirds of patients who die succumb within 16 hours after hospital admission. ${ }^{3-5}$ 7-9 These alarming data emphasise the need for a prompt diagnosis.
The presence of skin lesions usually raises the suspicion of a meningococcal infection. In meningococcal meningitis this suspicion is confirmed by the presence of Gram negative diplococci in cerebrospinal fluid on staining, a process that takes less than one hour. In meningococcal sepsis, however, Gram staining of cerebrospinal fluid often gives negative results for meningococci. As cultures of blood and cerebrospinal fluid yield results only after 12-24 hours and other diseases may present with similar lesions, the initial treatment of meningococcal sepsis is often given blind with respect to the causative micro-organism Yet, a prompt bacteriological diagnosis is one of the prerequisites for saving lives. In 1917 Netter and Salanier noted the presence of diplococci in a smear of a skin lesion. ${ }^{10}$ Later they successfully cultured meningococci from such a lesion. "In the following decades this method did not become generally accepted and only a few studies report on it..$^{12}$ In 1944 Bernhard and Jordan stated: "We, like many others, were not appreciative of the tremendous value of the stained smear...."14 Nearly half a century later we believe that this statement is still true for many doctors.

In view of these considerations, we studied retrospectively the diagnostic value of Gram staining samples from skin lesions of patients with meningococcal infections.

\section{Patients and methods}

From October 1990 to May 1992, 45 patients with subsequently proved acute meningococcal infections were admitted to St Laurentius Hospital, a community hospital in the south of the Netherlands. Thirty four patients presented with skin lesions. Needle aspiration of a skin lesion was performed in 26 patients (16 females, age range 6 months to 72 years (median 12.5 years)) immediately after they were admitted to the hospital and before any antibiotics were given. Twenty five patients had haemorrhagic lesions and one had a rash.

From 1989 to 1993,33 patients with life threatening meningococcal infections were referred to the intensive care unit of the University Hospital in Nijmegen. Thirty two had skin lesions. Punch biopsy of a skin lesion was performed in 25 patients ( 15 females, age range 7 months to 48 years (median 14 years)) some time after their admission to the unit; at the time of biopsy all patients were receiving antibiotic treatment. Twenty four patients had haemorrhagic skin lesions and one had a macular rash.

Aspiration was performed by the doctor in charge (paediatrician, neurologist, or physician), who inserted a needle into the centre of a petechial spot at an angle almost parallel with the skin. Some of aspirated fluid was put on to a glass slide with a cottonwool bud and
Dr $M$ van Deuren,

Department of Interna Medicine.

$B M F$ 1993;306:1229-32 
transported immediately to the nearby laboratory for Gram staining; the remaining fluid was used for culturing. Punch biopsy was performed by a dermatologist. At the laboratory a smear was made by squeezing a part of the dry specimen between two glass slides. The smear was Gram stained, the remaining part was cultured. The complete procedure, from sampling to microscopic examination of the Gram stained specimen, took about $\mathbf{4 5}$ minutes.

Patients were retrospectively divided into four groups based on their clinical manifestations. ${ }^{215}$ Patients in group A had meningococcaemia without meningitis or shock, those in group B had meningitis, those in group $C$ had both meningitis and shock, and those in group D had septic shock without meningitis. Meningitis was defined as a leucocyte count of greater than $100 \times 10^{\circ} / 1$ in cerebrospinal fluid with a decreased glucose concentration and increased protein concentration or nuchal rigidity, or both. A definitive classification according to these criteria was not possible in three patients who underwent needle aspiration as their leucocyte count was borderline $(104,110$, and $\left.121 \times 10^{6} / 1\right)$ and glucose and protein concentrations were normal with no nuchal rigidity. These three patients were classed as having no meningitis (one in group A and two in group D). Shock was defined as a systolic blood pressure of less than $100 \mathrm{~mm} \mathrm{Hg}$ in adults, of less than $85 \mathrm{~mm} \mathrm{Hg}$ in children younger than 14 years, and of less than $75 \mathrm{~mm} \mathrm{Hg}$ in children younger than 4 years. ${ }^{21617}$ In four patients who underwent needle aspiration blood pressure was not noted in the medical records, but other signs of insufficient endorgan perfusion were included, such as acute change in mental state without meningitis, metabolic acidosis, increased serum creatinine concentration, and diffuse intravascular coagulation. ${ }^{18}$

Seven of the 26 patients who had needle aspiration were in group A, nine were in group B, three in group $C$, and seven in group D. Three patients died (one in each of the groups B, C, and D). Ten of the 25 patients who underwent punch biopsy were in group $B$, four were in group C, and 11 in group D. Three of them (all in group D) died.

\section{Results}

Table I shows the microbiological results in all 51 patients. Bacteria were detected in the skin lesions of $16(62 \%$ (95\% confidence interval $41 \%$ to $80 \%)$ ) of the 26 patients who underwent needle aspiration; in nine patients staining and culture gave positive results, in three staining gave positive and culture negative results, and in four culture gave positive and staining negative results. In nine out of 10 patients with shock (groups C and D) skin lesions contained bacteria; in seven of them staining and culture gave positive results
TABLE II-Results of Gram staining of skin lesions and cerebrospinal fluid in 51 patients. Values are numbers of patients

\begin{tabular}{lcc}
\hline & \multicolumn{2}{c}{ Cerebrospinal fluid } \\
\cline { 2 - 3 } & Positive & Negative or absent ${ }^{\star}$ \\
\hline Skin lesion: & & \\
Positive & 10 & 16 \\
Negative & 21 & 4 \\
\hline
\end{tabular}

*No cerebrospinal fluid available in two patients because lumbar puncture was contraindicated.

TABLE III-Results of Gram staining of skin lesions and cerebrospinal fluid in 18 patients with shock without meningitis (group D). Values are numbers of patients

\begin{tabular}{lcc}
\hline & \multicolumn{2}{c}{ Cerebrospinal fluid } \\
\cline { 2 - 3 } & Positive & Negative or absent \\
\hline Skin lesion: & & \\
Positive & 1 & 2 \\
Negative & 3 & 2 \\
\hline No cerebrospinal fluid available in two patients because lumbar puncture
\end{tabular}

was contraindicated.

and in two culture gave positive results and staining negative results.

Meningococci were detected in the skin lesions of 16 $(64 \%(42 \%$ to $82 \%))$ of the 25 patients who underwent punch biopsy; in nine staining and culture gave positive results, in five only Gram staining gave positive results, and in two only culture gave positive results. Bacteria were detected in 14 of the 15 patients with shock: in nine staining and culture both gave positive results, in four only staining gave positive results, and in one only culture gave positive results.

Positive results on Gram staining a sample from a skin lesion or a sample of cerebrospinal fluid enables rapid diagnosis. Table II shows the results of such staining in the two types of sample. The sensitivity of staining a skin lesion was $51 \%$ and did not differ significantly from the sensitivity of staining cerebrospinal fluid $(61 \%)$ (McNemar's test, $p=0 \cdot 41$ ). However, the additional informative value of positive results from a skin lesion was obvious. In $16(80 \%)$ of the 20 patients with inconclusive results from staining of cerebrospinal fluid the results for the skin lesion provided the diagnosis. When only the critically ill patients with sepsis but no meningitis (group D, table III) were considered, the sensitivity of Gram staining of skin lesions increased to $72 \%$ and differed significantly from the sensitivity of staining cerebrospinal fluid $(22 \%)$ (McNemar's test, $\mathrm{p}<0.05)$. In patients with meningitis without shock (group B) Gram staining of the skin lesion was less informative: in only three $(16 \%)$ of the 19 patients were Gram negative diplococci shown in the skin. This low sensitivity contrasted significantly with the high yield in patients with meningitis and shock (group $\mathrm{C}$ ) in whom bacteria

TABLE I-Microbiological results in 51 patients with acute meningococcal infection who underwent needle aspiration or punch biopsy of skin lesions before or after antibiotic treatment, respectively *

\begin{tabular}{|c|c|c|c|c|c|c|c|c|}
\hline \multirow[b]{2}{*}{ Group } & \multirow[b]{2}{*}{ Procedure } & \multirow[b]{2}{*}{$\begin{array}{c}\text { No of } \\
\text { patients }\end{array}$} & \multicolumn{3}{|c|}{ Cerebrospinal fluid } & \multicolumn{3}{|c|}{ Skin lesion } \\
\hline & & & $\begin{array}{l}\text { Proportion } \\
\text { (\%) with } \\
\text { positive } \\
\text { results on } \\
\text { Gram } \\
\text { staining }\end{array}$ & $\begin{array}{l}\text { Proportion } \\
\text { (\%) with } \\
\text { positive } \\
\text { results on } \\
\text { culture }\end{array}$ & $\begin{array}{l}\text { Proportion } \\
\text { (\%) with } \\
\text { positive } \\
\text { results on } \\
\text { blood } \\
\text { cultures }\end{array}$ & $\begin{array}{c}\text { Median } \\
\text { (range) } \\
\text { duration of } \\
\text { antibiotic } \\
\text { treatment } \\
\text { before } \\
\text { biopsy (h) }\end{array}$ & $\begin{array}{l}\text { Proportion } \\
\text { (\%) with } \\
\text { positive } \\
\text { results on } \\
\text { Gram } \\
\text { staining }\end{array}$ & $\begin{array}{l}\text { Proportion } \\
\text { (\%) with } \\
\text { positive } \\
\text { results on } \\
\text { culture }\end{array}$ \\
\hline A (meningococcaemia) & $\begin{array}{l}\text { Needle aspiration } \\
\text { Punch biopsy }\end{array}$ & $\begin{array}{l}7 \\
0\end{array}$ & $\begin{array}{c}2 / 7(29) \\
-\end{array}$ & $\begin{array}{c}2 / 7(29) \\
-\end{array}$ & $\begin{array}{c}2 / 7(29) \\
-\end{array}$ & 0 & $\begin{array}{c}3 / 7(43) \\
-\end{array}$ & $\begin{array}{c}3 / 7(43) \\
-\end{array}$ \\
\hline B (meningitis) & $\begin{array}{l}\text { Needle aspiration } \\
\text { Punch biopsy }\end{array}$ & $\begin{array}{r}9 \\
10\end{array}$ & $\begin{array}{r}9 / 9(100) \\
10 / 10(100)\end{array}$ & $\begin{array}{r}9 / 9(100) \\
10 / 10(100)\end{array}$ & $\begin{array}{l}2 / 9(22) \\
1 / 6(17)\end{array}$ & $\begin{array}{l}0 \\
4(0 \cdot 2-24)\end{array}$ & $\begin{array}{r}2 / 9(22) \\
1 / 10(10)\end{array}$ & $\begin{array}{r}1 / 9(11) \\
1 / 10(10)\end{array}$ \\
\hline C (meningitus with shock) & $\begin{array}{l}\text { Needle aspiration } \\
\text { Punch biopsy }\end{array}$ & $\begin{array}{l}3 \\
4\end{array}$ & $\begin{array}{l}3 / 3(100) \\
3 / 4(75)\end{array}$ & $\begin{array}{l}3 / 3(100) \\
2 / 4+(50)\end{array}$ & $\begin{array}{l}1 / 3(33) \\
2 / 4(50)\end{array}$ & $\begin{array}{l}0 \\
7(3-20)\end{array}$ & $\begin{array}{l}3 / 3(100) \\
4 / 4(100)\end{array}$ & $\begin{array}{l}3 / 3(100) \\
3 / 4(75)\end{array}$ \\
\hline $\begin{array}{l}\text { D (septic shock without } \\
\text { meningitis) }\end{array}$ & $\begin{array}{l}\text { Needle aspiration } \\
\text { Punch biopsy }\end{array}$ & $\begin{array}{r}7 \\
11\end{array}$ & $\begin{array}{r}3 / 6(50) \\
1 / 10(10)\end{array}$ & $\begin{array}{r}3 / 6(50) \\
6 / 10(60)\end{array}$ & $\begin{array}{l}1 / 6(16) \\
8 / 8(100)\end{array}$ & $\begin{array}{l}0 \\
12 \cdot 5(0 \cdot 1-60)\end{array}$ & $\begin{array}{r}4 / 7(57) \\
9 / 11(82)\end{array}$ & $\begin{array}{r}6 / 7(86) \\
7 / 11(64)\end{array}$ \\
\hline
\end{tabular}

*Venepuncture and lumbar puncture were performed before antibiotic treatment.

IIn one patient lumbar puncture was performed 21 hours after the start of antibiotics; Gram staining of fluid gave positive results and culture negative results. 
were detected in all of the Gram stained skin lesions (Fisher's exact test, $\mathrm{p}<0.001$ ).

Among the 25 patients admitted to the intensive care unit, 16 were referred from other hospitals after a median delay of 6 hours (range 1-59) and nine were transferred from the emergency unit. All received antibiotics before admission. At punch biopsy these patients had been taking antibiotics for a median duration of 6 hours (range 10 minutes to 60 hours). Table IV shows the microbiological results of the biopsy specimens. Meningococci were cultured from specimens in patients with shock up to 13 hours after the start of antibiotic treatment and detected by Gram stain as late as $\mathbf{4 5}$ hours after the start of treatment.

TABLE IV-Results of Gram staining and culture of skin biopsy specimens in 25 patients admitted to intensive care unit

\begin{tabular}{|c|c|c|c|c|}
\hline Group & $\begin{array}{l}\text { Case } \\
\text { No }\end{array}$ & $\begin{array}{l}\text { Time between start of } \\
\text { antibiotics and biopsy } \\
\text { (h) }\end{array}$ & $\begin{array}{c}\text { Gram } \\
\text { staining }\end{array}$ & Culture \\
\hline B (meningitis) & $\begin{array}{r}1 \\
2 \\
3 \\
4 \\
5 \\
6 \\
7 \\
8 \\
9 \\
10\end{array}$ & $\begin{array}{r}0 \cdot 2 \\
0 \cdot 6 \\
2 \cdot 5 \\
3 \\
4 \\
4 \\
5 \\
5 \\
18 \\
24\end{array}$ & $\begin{array}{l}\text { Negative } \\
\text { Negative } \\
\text { Negative } \\
\text { Negative } \\
\text { Negative } \\
\text { Negative } \\
\text { Negative } \\
\text { Negative } \\
\text { Negative } \\
\text { Positive }\end{array}$ & $\begin{array}{l}\text { Negative } \\
\text { Negative } \\
\text { Negative } \\
\text { Negative } \\
\text { Negative } \\
\text { Positive } \\
\text { Negative } \\
\text { Negative } \\
\text { Negative } \\
\text { Negative }\end{array}$ \\
\hline $\begin{array}{l}\mathrm{C} \text { (meningitis with } \\
\text { shock) }\end{array}$ & $\begin{array}{l}11 \\
12 \\
13 \\
14\end{array}$ & $\begin{array}{r}3 \\
7 \\
7 \\
20\end{array}$ & $\begin{array}{l}\text { Positive } \\
\text { Positive } \\
\text { Positive } \\
\text { Positive }\end{array}$ & $\begin{array}{l}\text { Positive } \\
\text { Positive } \\
\text { Positive } \\
\text { Negative }\end{array}$ \\
\hline $\begin{array}{l}\mathrm{D} \text { (septic shock } \\
\text { without } \\
\text { meningitis) }\end{array}$ & $\begin{array}{l}15 \\
16 \\
17 \\
18 \\
19 \\
20 \\
21 \\
22 \\
23 \\
24 \\
25\end{array}$ & $\begin{array}{l}0 \cdot 1 \\
3 \\
4 \\
6 \\
11 \\
12 \cdot 5 \\
13 \\
22 \cdot 5 \\
44 \\
45 \\
60\end{array}$ & $\begin{array}{c}\text { Positive } \\
\text { Positive } \\
\text { Positive } \\
\text { Negative } \\
\text { Positive } \\
\text { Positive } \\
\text { Positive } \\
\text { Positive } \\
\text { Positive } \\
\text { Positive } \\
\text { Negative }\end{array}$ & $\begin{array}{l}\text { Positive } \\
\text { Positive } \\
\text { Positive } \\
\text { Positive } \\
\text { Positive } \\
\text { Positive } \\
\text { Positive } \\
\text { Negative } \\
\text { Negative } \\
\text { Negative } \\
\text { Negative }\end{array}$ \\
\hline
\end{tabular}

\section{Discussion}

Our results show the value of needle aspiration or punch biopsy of skin lesions for the prompt diagnosis of acute meningococcal infections. Haemorrhagic skin lesions are considered to be characteristic for meningococcal infections.' Similar lesions may, however, be encountered in septicaemia due to pneumococci, staphylococci, Haemophilus influenzae, Capnocytophaga canimorsus, or viral infections as well as in non-infectious diseases. In $10-25 \%$ of all meningococcal infections no skin lesions are present. ${ }^{19} 20$ Skin manifestations vary from an exanthematous rash, ${ }^{21} 22$ to erythematous maculopapules or haemorrhagic lesions. ${ }^{193}$ Their presence and development mirrors the course of the disease and may be used as a prognostic factor. ${ }^{719}$ The development within a few hours of numerous, rapidly extending, haemorrhagic lesions is associated with a fulminant course, as is seen in sepsis. Development may be slower in patients with a more protracted course of meningitis. ${ }^{23}{ }^{24}$ In our study skin lesions were absent in 11 of the 45 patients (24\%) admitted to the general hospital and in one of the 33 patients (3\%) admitted to the intensive care unit.

The pathogenesis of skin lesions in meningococcal disease is not well understood. Originally, meningococci were thought to damage the endothelium by their direct presence in capillaries. ${ }^{23}{ }^{25}$ The current view is that the generalised Shwartzman reaction is a cytokine primed vasculitis, mediated by the upregulation of adhesion molecules on leucocytes and endothelium..$^{26-28}$ Meningococci, meningococcal endotoxin, and several cytokines induced by endotoxin are able to induce this process independently. Therefore, skin lesions may develop without the direct presence of bacteria. We used two different techniques, needle aspiration and punch biopsy, to obtain material from a skin lesion. Needle aspiration is attractive in emergency cases as it can be performed by the attending doctor in an accident and emergency department. The drawback is that the amount of aspirated material is limited, which might increase the risk of false negative results caused by sampling error. Punch biopsy provides more material, yet the sensitivity of both methods examined by Gram staining and culture was similar (respectively $62 \%$ and $64 \%$ ).

Meningococci could be detected in skin lesions by one of these methods in $32(63 \%)$ out of 51 patients; 26 $(51 \%)$ had positive results on staining. For comparison, only reports from the first half of this century are available. Smears gave positive results on staining in $83 \%, 80 \%, 68 \%$, and $70 \%$ of the patients at admission and in all patients at necropsy. ${ }^{12-1423} 29$ Cultures gave positive results in $88 \% .{ }^{14}$ Our lower yield may partly be explained by the preceding use of antibiotics in 25 patients. The duration of preclinical disease and the probably more advanced infection in the older studies also may be important-for example, in the study of Hoyne and Brown in 1948 the mean duration of preclinical disease was $3 \cdot 1$ days ${ }^{29}$ compared with $17 \cdot 1$ hours in our study. None of the older studies differentiated between meningococcaemia, meningitis, and sepsis.

We found that skin lesions were particularly informative in patients with meningococcal sepsis. In 14 of these 18 patients diagnosis was not possible from the results of Gram staining of cerebrospinal fluid, whereas Gram staining of skin lesions provided the diagnosis in $12(86 \%)$ of these 14 patients. As it takes 12 to 24 hours for a culture to yield positive results and only 45 minutes to complete Gram staining of a sample from a skin lesion, staining can speed up the diagnosis considerably. Rapid diagnosis is important because in about two thirds of all fatal cases the patients die within 16 hours after admission ${ }^{3-5} 7.9$ and because additional therapeutic options such as plasma exchange improve outcome only when started at an early stage. ${ }^{16}$ Prognosis is also improved by prompt antibiotic treatment. ${ }^{30-34}$ However, antibiotics are often not given early because they might hamper the bacteriological diagnosis. We found that in patients with shock bacteria were visualised in the Gram stained skin lesion in 13 out of 15 patients up to 45 hours after start of antimicrobial treatment and isolated from skin lesions up to 13 hours after start of the antibiotics. Therefore, in patients with suspected meningococcal shock the first antibiotic dose need not be deferred until after the collection of spinal fluid or blood for culturing.

We also found that in patients with meningitis but no shock bacteria were detected in the stained skin lesion only in $16 \%$ of the patients, whereas in all seven patients with meningitis and shock the Gram stained skin lesion gave positive results $(p<0.001)$. This suggests that this difference can be used as an additional prognostic sign - that is, a positive result of a Gram stained skin smear of a currently stable patient with meningitis may alert the clinician to haemodynamic deterioration.

New molecular techniques for the rapid diagnosis of infections have been developed ${ }^{35}{ }^{36}$ and may be suitable for biopsy specimens from skin lesions, perhaps with a greater sensitivity.

\section{Conclusion}

We showed that in suspected meningococcal disease Gram staining and culture of haemorrhagic skin lesions are useful diagnostic tools, especially in patients with sepsis. The results from the Gram stain may accelerate 
the diagnosis by nearly one day and prompt earlier adequate treatment. Furthermore, we showed that meningococci are still present in skin lesions of patients with sepsis several hours after the start of antimicrobial treatment. Immediate administration of antibiotics by the first doctor considering a diagnosis of meningococcal sepsis will therefore not disturb proper diagnosis. Finally, the finding of diplococci in Gram stained skin lesions in a patient with meningitis may warn the clinician of possible deterioration.

Seventy six years after Gram negative diplococci were described in skin lesions by Netter and Salanier we can still endorse the statement of Hill and Kinney made 30 years later: "it is surprising that biopsy as a diagnostic adjunct has not gained more widespread recognition." ${ }^{23}$

1 Apicella MA. Neisseria meningitidis. In: Mandell GL, Douglas RG, Bennett $\mathrm{JE}$, eds. Principles and practice of infectious diseases. New York: Churchill Livingstone, 1990: 1600-13.

2 Halstensen A, Pedersen SHJ, Haneberg B, Bjorvatn B, Solberg CO. Case fatality of meningococcal disease in Western Norway. Scand $\mathcal{f}$ Infect Dis 1987;19:35-42.

3 Cahalane SF, Waters $M$. Fulminant meningococcal septicaemia. A hospital experience. Lancet 1975 ;ii:120-1.

4 McGehee WG, Rapaport SI, Hjort PF. Intravascular coagulation in fulminant meningococcemia. Ann Intern Med 1967; 67:250-60.

5 Mercier J-C, Beaufils F, Hartmann J-F, Azéma D. Hemodynamic patterns of meningococcal shock in children. Crit Care Med 1988;16:27-34.

6 Giraud T, Dhainaut J-F, Schremmer B, Regnier B, Desjars P, Loirat P, et al. Adult overwhelming meningococcal purpura. A study of 35 cases, Adult overwhelming meningococcal purpura.

7 NIklasson P-M, Lundbergh P, Strandell T. Prognostic factors in meningococcal disease. Scand I Infect Dis 1971;3:17-25.

8 Manios SG, Kanakoudi F, Maniati E. Fulminant meningococcemia. Heparin therapy and survival rate. Scand $\mathcal{F}$ Infect Dis 1971;3:127-33.

9 Emperanza JI, Aldamiz-Echevarria L, Perez-Yarza EG, Larranăa P, Jiminez $\mathrm{JL}$, Labiano M, et al. Prognostic score in acute meningococcemia. Crit Care Med 1988;16:168-9.

10 Netter A, Salanier $M$. The presence of meningococci in the purpuric elements of meningococcal infection. British fournal of Children's Diseases 1917;14: 101-4.

11 Netter A, Salanier $M$, Blanchier $M$. Two fresh cases of meningococcal infection with presence of meningococcus in the purpuric eruption: cultivation of the meningococcus from the serum of a vesicle in one of the cases; occurrence of a strain of meningococci differeing from the typical meningococcus. British fournal of Children's Diseases 1917;14:264-6.

12 McLean S, Caffey J. Endemic purpuric meningococcus bacteremia in early life: the diagnostic value of smears from the purpuric lesions. Am $f$ Dis Child 1931;42:1053-74

13 Tompkins VN. The diagnostic value of smears from purpuric lesions of the skin in meningococcic disease. $f A M A 1943 ; 123: 31-2$.
14 Bernhard WG, Jordan AC. Purpuric lesions in meningococcic infections. Diagnosis from smears and cultures of the purpuric lesions. $7 \mathrm{Lab}$ Clin Med 1944;29:273-81.

15 Waage A, Brandzaeg P, Halstensen A, Kierulf P, Espevik T. The complex pattern of cytokines in serum of patients with meningococcal septic shock. Association between interleukin 6, interleukin 1, and fatal outcome. $\mathcal{J}$ Exp Med 1989;169:333-8.

16 Van Deuren M, Santman FW, Van Dalen R, Sauerwein RW, Span LFR, Van der Meer JWM. Plasma and whole blood exchange in meningococcal sepsis. Clin Infect Dis 1992;15:424-30.

17 Sinclair JF, Skeoch CH, Hallworth D. Prognosis of meningococcal septicaemia. Lancet 1987;ii:38.

18 Bone RC, Fisher CJ, Clemmer TJ, Slotman GJ, Metz GA, Balk RA, et al. Sepsis syndrome: a valid clinical entity. Crit Care Med 1989;17:389-93.

19 Toews WH, Bass JW. Skin manifestations of meningococcal infection. An immediate indicator of prognosis. Am $\mathcal{F}$ Dis Child 1974;127:173-6.

20 Brandtzaeg P, Dahle JS, Høiby EA. The occurrence and features of hemorrhagic skin lesions in 115 cases of meningococcal disease. NIPH Ann 1983;6:183-90, 202-3

21 Rubenstein R, Esterley NB. Meningococcal meningitis with a benign skin rash. Pediatr Dermatol 1986;3:414-6.

22 Baxter P, Priestley B. Meningococcal rash. Lancet 1988;i: 1166-7.

23 Hill WR, Kinney TD. The cutaneous lesion in acute meningococcemia. fAMA 1947;134:513-8.

24 Tonjum T, Nilsson F, Bruun JN, Haneberg B. The early phase of meningococcal disease. NIPH Ann 1983;6:175-81.

25 Dahle JS. Pathogenesis of hemorrhagic skin lesions in meningococcal disease. NIPH Ann 1983;6:49-53.

26 Davis CE, Arnold K. Role of meningococcal endotoxin in meningococcal purpura. $f$ Exp Med 1974;140:159-71.

27 Movat HZ, Burrowes CE. The local Shwartzman reaction: endotoxinmediated inflammatory thrombo-hemorrhagic lesions. In: Berry LJ, ed. Handbook of endotoxin. Vol 3. Cellular biology of endotoxin. Amsterdam: Elsevier, 1985:260-302.

28 Argenbright LW, Barton RW. Interactions of leucocyte integrins with intercellular adhesion molecule 1 in the production of inflammatory vascular injury in vivo. 7 Clin Invest 1992;89:259-72.

29 Hoyne AL, Brown RH. 727 Meningococcic cases: an analysis. Ann Intern Med 1948;28:248-59.

30 Talan DA, Hoffman JR, Yoshikawa TT, Overturf GD. Role of empiric parenteral antibiotics prior to lumbar puncture in suspected bacterial meningitis: state of art. Rev Infect Dis 1988;10:365-76.

31 Gedde-Dahl TW, Høiby EA, Eskerud JR. Unbiased evidence on early treatment of suspected meningococcal disease. Rev Infect Dis 1990;12: 359-63.

32 Kilpi T, Anttila M, Kallio MJT, Peltola H. Severity of childhood bacterial meningitis and duration of illness before diagnosis. Lancet 1991;ii:406-9.

33 Strang JR, Pugh EJ. Meningococcal infections: reducing the case fatality rate by giving penicillin before admission to the hospital. $B M \mathcal{F}$ 1992;305:141-7.

34 Begg N. Reducing mortality from meningococcal disease. BMf 1992;305: 133-4.

35 Tomplins LS. The use of molecular methods in infectious diseases. $N$ Engl $f$ Med 1992;327:1290-7.

36 Haolin NI, Knight AI, Cartwright K, Palmer WH, McFadden J. Polymerase chain reaction for diagnosis of meningococcal meningitis. Lancet 1992;ii: $1432-4$.

(Accepted 2 March 1993)
Tayside Health Board, Dundee DD1 9NL

Trevor Smith, information services officer

$B M F$ 1993;306:1232-5

\section{Influence of socioeconomic factors on attaining targets for reducing teenage pregnancies}

Trevor Smith

Abstract

Objective-To determine the rate of pregnancy and outcome in teenagers in areas of different socioeconomic conditions, and to assess the implication for achievement of government and local targets in reducing unwanted pregnancies in teenagers.

Design-Records of pregnancies were obtained from hospital discharge files and rates of live and still births and abortions calculated for each postcode sector. Postcodes were grouped by categories of deprivation and by local government district. Setting-Tayside, Scotland.

Subjects-Teenage girls admitted to National Health Service hospitals for delivery or abortion in 1980-90.

Main outcome measures-Conception in girls aged under 16 by area of residence and relative proportion leading to live births or terminations. Rate of different outcomes in girls under the age of 20 by area of residence.

Results-The pregnancy rate in girls aged under 16 was three times as high, and in all girls under 20 six times as high in the most deprived areas as in the most affluent areas. The proportion of teenage pregnancies ending in abortions was higher in the affluent areas, where two out of three ended in abortion compared with one out of four in the deprived areas.

Conclusions-Although there was a higher pregnancy rate in teenagers in more deprived areas, the proportion ending in abortion was greater in more affluent areas, possibly due to social and parental pressure. The wide geographical variation in patterns of teenage pregnancy indicates the need for a small area rather than a regional approach to setting targets and devising measures of achieving them.

\section{Introduction}

In its white paper The Health of the Nation the government set a target for reducing the conception rate in girls aged under 16 by at least $50 \%$ by the year 2000 from the 1989 figure of 9.5 per 1000 girls aged 13 to 15 to no more than $4 \cdot 8$ per $1000 .^{1}$ Although it would be wrong to assume that all pregnancies in these girls 